\title{
Secularismo e Espiritismo nas Ciências Sociais: dis- cutindo os resultados da UFRGS
}

Bernardo Lewgoy

\section{Introdução}

Em recente pesquisa, realizada sob a liderança do Núcleo de Estudos de Religião da UFRGS (STEIL et alii, 2001), investigou-se os pertencimentos e atuações políticos e religiosos dos estudantes de Ciências Sociais em diferentes universidades do país. Além da notável apresentação dos dados, pediu-se que pesquisadores comentassem os resultados por universidade, propondo caminhos interpretativos para entender os nexos entre essas dimensões tradicionalmente totalizantes da experiência social.

Ora, uma proposta de investigação desse tipo está relacionada com um socrático desejo de autoconhecimento, considerando-se que nós, pesquisadores na área de religião (e, também, sujeitos políticos), estamos lidando com a religiosidade de nossos possíveis sucessores. Para estes, não se deixa de transpor algumas das indagações que são dirigidas aos cientistas sociais da religião: caso eles sejam portadores das marcas de uma origem ou trajetória religiosa, senão na base familiar pelo menos como um inconsciente intelectual e afetivo, no mesmo movimento que os aproximaria de um estudo científico da religião, haveria uma mácula de base que os separaria do bom distanciamento científico, como uma derivação do que tem sido chamado de "ateísmo metodológico"? Por exemplo, caso o índice de ateus supere o de religiosos, há boas chances de desfrutarmos de condi-

Bernardo Lewgoy é professor adjunto do Departamento de Antropologia da UFRGS e membro do Núcleo de Estudos de Religião (NER).

Debates do NER, Porto Alegre, ano 2, n. 2, p. 103-116, agosto de 2001 
ções ótimas de criação e reprodução de uma boa ciência social da religião? Ora, isso só seria verdadeiro se pudéssemos estabelecer correlações lineares entre resultados codificados da pesquisa e adesões subjetivas, mas os dados de que dispomos infelizmente não têm essa eloqüência, e ficamos restritos ao terreno da conjetura. No terreno da religião, o exercício estatístico permite-nos indicar e comparar tendências, mas a densidade dos dados exige uma abordagem qualitativa complementar, em virtude de um campo de possibilidades em que as categorias não descrevem práticas, pertencimentos e engajamentos de modo unívoco. Quando a religiosidade não se identifica com a declaração de filiação religiosa - seguro indício, portanto, da atual fase de pluralismo religioso - há sempre chances de encontrarmos identidades religiosas flutuantes, cujas combinações com o engajamento político são as mais amplas possiveis. No estágio atual, podemos apenas dirimir dúvidas e levantar questões.

Uma visão ampla dos dados colhidos nas diferentes universidades permite-nos afirmar que, regra geral, o comportamento político e o consumo de bens culturais têm uma maior uniformidade do que a adesão, identificação ou engajamento religioso dos entrevistados, o qual tem um espectro relativamente maior de variação no cenário da pesquisa. No universo pesquisado, a maioria dos estudantes de Ciências Sociais é de eleitores do PT, lê os clássicos da literatura brasileira e manifesta um gosto musical que mais revela disposições próprias a uma certa idade num segmento social específico (jovens universitários adultos de camadas médias urbanas intelectualizadas, com idades aproximadas entre 18 e 25 anos) do que propriamente singulariza radicalmente opções e papéis, em que pesem outras diferenças regionais nos resultados sobre religião e religiosidade. Ou seja, semelhantes quanto às referencias literárias, políticas e musicais, os dados em questão expressam a pressão de uma órbita cultural global e geracional na constitui- 
ção de identidades e estilos de vida de jovens universitários. Já os dados sobre religiosidade são bastante reveladores, se comparativamente considerados, de influências do grupo familiar e de um campo religioso local, particularizando identidades e pertencimentos sociais.

Vou me centrar, neste artigo, nos dados que revelam uma maior discrepância em relação aos outros cursos do universo pesquisado e que apontam as Ciências Sociais da UFRGS como uma espécie de campeã do secularismo e do espiritismo no país. Sustento que esses dois fatores, se aliados com o filtro representado pelo vestibular na universidade pública, mais a situação histórica peculiar do Rio Grande do Sul, são as chaves para o entendimento da singularidade das informações obtidas.

\section{Interpretando os dados: secularismo e espiritismo}

A UFRGS é a mais antiga e prestigiada universidade pública do Rio Grande do Sul. Com o corpo docente mais qualificado do estado e oferecendo um ensino público e gratuito de qualidade, seus cursos encontram-se entre os mais procurados pelos estudantes. Apesar dos baixos investimentos em infra-estrutura por parte do governo federal ao longo dos anos 90, a imagem de um campus estudantil laico e secularizado, onde os jovens acadêmicos experimentam um ethos individualista ligado ao exercício da liberdade e da crítica, expressa-se em todo um estilo de vida, tratando-se de jovens estudantes (de 18 a 25 anos, ou seja, a maior parte dos entrevistados).

Por dispor de um curso noturno ao lado de um diurno, a UFRGS goza de uma posição privilegiada nesta pesquisa, na medida em que é possivel exercer uma frutífera comparação, devido às relevantes diferenças entre os perfis médios dos alunos durante os turnos. Ou seja, ainda que o curso noturno da UFRGS, mais recente, sirva como contraponto especificante em termos de idade, trajetória social e opções 
políticas e religiosas de seus membros, é o curso diurno que melhor representa a tradição de um certo modelo laico, cívico e genericamente oposicionista de "academia". Neste modelo, agora em transição, as Ciências Sociais são representadas externamente como uma vocação socialmente ambígua, como parte de um estilo de vida e de uma visão de mundo disponiveis às camadas médias urbanas brasileiras nas últimas décadas.

Como indicado em texto anterior (STEIL et alii, 2001), no curso diurno da UFRGS, 64,9\% dos alunos definem-se como "sem religião" e $35,1 \%$ "com religião" numa pergunta de escolha simples ("com ou sem religião?"), contra 46,3\% de "sem religião" versus 53,7\% que se declararam "com religião" no curso noturno. Ora, essa pergunta afigura-se como um divisor de águas na delimitação de um posicionamento existencial mais geral.

Na pergunta que especifica a definição, temos a seguinte distribuição dos resultados: $29,7 \%$ dos alunos do diurno da UFRGS definem-se como "religiosos", contra 41,5\% no noturno. Já os que se declararam sem religião totalizaram $28,4 \%$ no diurno contra $26,4 \%$ no noturno; $21,6 \%$ de agnósticos no diurno contra $15,6 \%$ no noturno. Na alternativa "ateu", contamos $20,3 \%$ assim declarados no diurno contra $17,4 \%$ no noturno.

Somando-se as colunas "ateu" e "sem religião", temos o que poderia se chamar de um núcleo de secularismo no diurno que chega a $48,7 \%$ dos entrevistados, ou seja, configuram, neste turno, um espectro de pessoas para quem a afirmação de uma postura existencial desfiliada de uma agremiação religiosa é básica na conformação de sua identidade atual. Ou seja, esse estrato contém as atitudes mais inspiradas pelo secularismo na visão de mundo em que embebem a sua identidade, ainda que apenas a declaração de "ateu" implique num projeto concorrente com a religião e a religiosidade, em qualquer de suas formas. Para este núcleo de secularismo, é de vital importância o ânimo laicizante que 
impede que a religião interfira nas diferentes modalidades subjetivas de ser, bem como nas interações sociais do cotidiano. O que não deve ser confundido com a presença difusa de inquietações de ordem religiosa entre os estudantes da UFRGS, que apenas poderia ser percebida no âmbito de uma trajetória mais longa, pois remetem a dimensões imanentes da religiosidade, que permanecem, talvez, latentes num contexto de "desencantamento do mundo".

Por dedução, os outros 15,2\% dos que restam nos que se disseram "sem religião" no diurno devem ser colhidos entre os agnósticos, mas aí já não podemos afirmar uma ativa demarcação de uma fronteira secular na conformação da identidade desses agnósticos, mas sim um não-reconhecimento público de uma filiação institucional associado a possiveis indagações religiosas. Somando-se os 6,4\% de agnósticos restantes com os que se disseram religiosos, temos um núcleo religioso mais duro e identitário, com resultados muito próximos à primeira questão, podendo-se afirmar com segurança que a segunda questão replica a primeira com a única diferença de o agnóstico representar uma categoria "anfíbia”. Ou seja, confirma-se uma dissociação de princípio entre religiosidade e filiação religiosa, que aponta para a conhecida tese da privatização da consciência religiosa (ORO, 1997).

Não se pode afirmar que o índice de laicidade e secularismo do curso de Ciências Sociais da UFRGS seja o maior do país como o resultado de uma tendência recente, fruto de um contexto genericamente "sulista", em oposição a outras regiões do país. É justamente a comparação que faz emergir notáveis dessemelhanças entre a UFRGS e as outras faculdades de Ciências Sociais da mesma área geográfica, como a PUC e a UNISINOS, onde o nível de declaração nominal de pertencimento religioso apresenta resultados pelo menos inversos aos do curso de Ciências Sociais diurno da UFRGS. O contexto porto-alegrense, se comparado com outras cidades do país, como o Rio de Janeiro (este o segundo 
centro urbano do país e consagrado locus de visões de mundo e estilos de vida modernos) ou Belo Horizonte (de magnitude urbana comparável à capital gaúcha), não justificaria de per si a menor preocupação formal com a religião e com a religiosidade.

Sem dúvida, estamos diante de um ambiente altamente secularizado, como sói acontecer mesmo no mais confessional dos espaços acadêmicos, onde a regra é render-se aos resultados das ciências, ainda que colidam com algum posicionamento religioso. Nesse sentido, o baixo índice de adesão religiosa, e o comparativamente alto grau de ateísmo encontrado no diurno da UFRGS - que deve ser tomado literalmente como posição anti-religiosa e anti-teísta - apenas confirmariam a existência de um secularismo co-natural às Ciências Sociais se, e apenas se, isso pudesse confirmar-se como tendência mais ou menos homogênea em todas as universidades pesquisadas. O fato é que essas mesmas tendências que conformam uma matriz ideal típica na representação social das Ciências Sociais - influência do marxismo, da militância, de um ethos artístico, crítico e experimentalista na visão de mundo e estilo de vida - são pouco significativas na explicação das discrepâncias entre os resultados da UFRGS e os de outras universidades.

No entanto, se examinarmos as opções religiosas dos estudantes do diurno da UFRGS em relação à religião dos pais, veremos que o maior índice de laicidade dos filhos compatibiliza-se com os cerca de $60 \%$ de católicos nominais, o maior de todas as universidades, o que nos leva não propriamente a reiterar a inferência bastante tradicional de que as pessoas tendem a seguir a religião dos pais, mas que o contexto (anti?)-religioso familiar seguramente tem um peso significativo na conformação da resposta e opção dos entrevistados. No caso do curso noturno, o catolicismo nominal dos pais chega a cerca de 50\%, mas deve-se considerar que estamos lidando com um público mais velho e já inserido num mercado de trabalho, cujas chances de ensaiar uma 
carreira mainstream em Ciências Sociais - pós-graduações ou cargos profissionais de alto nível - são tendencialmente menores do que as dos seus colegas do dia. Nesse público social e profissionalmente diverso, de status comparativamente mais baixo e cujo capital social e cultural das famílias de origem é geralmente menos pujante do que o de seus colegas do diurno (de perfil mais próximo, portanto, dos alunos das universidades particulares), a religião é mais aceita do que para os seus colegas do dia. No entanto, a despeito das nítidas diferenças de perfil social, etário e de adesão religiosa em relação aos estudantes do dia, os estudantes do noturno pouco se diferenciam do diurno no que se refere ao comportamento eleitoral, o que nos sugere o desengate da religião de uma equação rígida com a política na maioria dos contextos pesquisados, religiosos e não-religiosos.

A importante presença do espiritismo no curso noturno é um dado que deve ser analisado em conjunto com a UNISINOS e a PUC. O número de espíritas encontrado em todas as universidades sulinas pesquisadas $(16,7 \%$ no noturno de Ciências Sociais da UFRGS, $14,3 \%$ na PUC e $10,8 \%$ na UNISINOS) é mais ou menos próximo (à exceção do diurno das CS da UFRGS - 6,6\%), e isso funciona como um indicador seguro de influências de um campo religioso local. Ao examinarmos a tabela 8 (de STEIL et alii, op. cit.), deparamo-nos com o dado de o espiritismo ser a religião mais praticada entre os que declararam ter uma religião no curso noturno, superando os praticantes de outras religiões, incluindo-se, é claro, os católicos (a6, 7\% de espíritas praticantes contra 5,6\% de católicos praticantes no noturno). A proporção de aproximadamente 3 espíritas praticantes para cada católico praticante não se altera no diurno $(6,6 \%$ de espíritas versus $1,3 \%$ de católicos), o que poderia nos sugerir uma tendência, mas infelizmente os limites da pesquisa não nos autorizam a extrapolar o terreno da indicação e da hipótese, para essa questão.

Maior no curso noturno, o espiritismo encontrado entre 
os acadêmicos de Ciências Sociais deve ser contextualizado no âmbito da tradição espírita no Rio Grande do Sul: este se afigura como racionalista, teísta e laico, herdeiro de um século de implantação entre os porto-alegrenses, sendo preferencialmente praticado, ainda que não exclusivamente, por camadas médias urbanas com segundo grau e curso superior ${ }^{1}$. Há também, no discurso e prática dos espíritas, uma nítida valorização do saber letrado enquanto signo de distinção e ética da escolaridade. A participação no espiritismo está constantemente associada a indivíduos em situação de ativa busca de mobilidade social através da trajetória escolar (cf. LEWGOY, 2000).

O espiritismo kardecista, se pensado no ambiente urbano de Porto Alegre, já pressupõe uma entourage ideológica secularizada, simpática aos raciocínios científicos, sem perda de compromisso com um horizonte teísta, mais ético e letrado do que fideísta, como uma espécie de candidato a suplementar a demanda religiosa reflexiva de um sujeito ético laico, que se sente afinado simultaneamente com o iluminismo e o cristianismo. Preferido entre os que declararam freqüentar uma religião no curso noturno, o subuniverso espírita é composto por indivíduos em média mais velhos, cuja fonte principal de sustento é um trabalho remunerado, ou seja, por informantes de um estrato de classes médias

\footnotetext{
${ }^{1}$ Nesse sentido, os dados que indicam um predominio de pessoas com maior índice de escolaridade entre os espíritas são comparáveis aos resultados descritos na pesquisa sobre religião e comportamento eleitoral, apresentada e discutida em Prandi \& Pierucci (1996). Obviamente, não se deve confundir os espíritas praticantes com os eventuais freqüentadores de centros espíritas em busca de algum serviço terapêutico ou religioso, que não se declarariam espíritas praticantes, nem com os seguidores de cultos afrobrasileiros, cuja identidade espírita assume, em alguns contextos, a conotação legitimadora pelo branqueamento, como um sucedâneo do catolicismo. Por observação pessoal, para alguns acadêmicos de Ciências Sociais que seguem a religião dos orixás, o orgulho está em diferenciar-se do kardecismo e não em neossincretizar-se para fins de legitimação.
} 
que não dispõem das mesmas facilidades e perspectivas dos alunos do diurno, aproximando-se mais das circunstâncias encontradas na PUC e na UNISINOS.

A identidade espírita entre futuros profissionais das $\mathrm{Ci}$ ências Sociais coloca interessantes problemas para a reflexão. Seria interessante analisar como esses informantes espíritas encaram possiveis discrepâncias entre os resultados críticos das Ciências Sociais e a doutrina espírita, na medida em que essa tradicionalmente carrega uma filosofia evolucionista, liberal e individualista em seu bojo, bem como uma sociologia de cunho normativo na apreciação da ordem social. Por conseqüência, há afinidades maiores com perspectivas de sociologia que se aproximam mais de um discurso crítico normativo sobre a sociedade? Há, paralelamente, um afastamento ou estranheza desses espíritas com relação a pontos de vista radicalmente relativistas e desenraizadores com um viés hermenêutico, como parece ser o caso da antropologia recente? A ciência social (ou o curso de Ciências Sociais, enquanto agência socializatória secundária) desmistifica, desencanta e seculariza, afinal de contas, ou abre as portas para um jogo de possibilidades articulatórias muito mais complexo em termos de reflexividade e identidade de seus estudantes?

Essas questões poderiam ser adaptadas a membresias de outras religiões, mas o ponto a ser relevado é a influência do fator "idade" nas mudanças de perfil das respostas às questões sobre pertencimento religioso. Se o secularismo predomina em ambos os turnos, ele parece ser abrandado com a idade. Nos alunos mais velhos (geralmente alocados no noturno), há uma tendência a ter menos preconceito e até maior aceitação de crenças e posturas religiosas, o que pode recolocar a reflexão sobre classes de idade em vista da posição do informante no ciclo da vida. 


\section{Secularização da politica entre estudantes de Ciênci- as Sociais: um fenômeno recente.}

Outro dado que merece alguma reflexão é o índice relativamente baixo de engajamento dos estudantes do noturno e do diurno em movimentos religiosos, políticos, estudantis, partidos, associações de bairro ou ONGs, ainda que a preferência por um voto "à esquerda" seja majoritária entre os alunos. Temos ali a situação de uma alta politização não combinada à participação ou engajamento em entidades ou movimentos da sociedade civil organizada. Nesse sentido, a tendência à baixa participação política, combinada ao voto de esquerda, converge com um retrato de um segmento de sociedade pluralista e desencantado com religião em seu vértice superior, cuja principal instância de participação cívica é a eleição, mas dissocia o estudante de Ciências Sociais de um estereótipo de militante que parecia caracterizá-lo anteriormente. Curiosamente, a taxa de engajamento político e social face à politização genérica parece replicar-se de modo simétrico no baixo engajamento religioso dentre aqueles que têm identificações religiosas (cerca de menos de $20 \%$ são engajados ou participam mais ativamente de movimentos políticos ou religiosos).

Tudo se passa como se não apenas a religião, mas também a política tivesse passado por uma secularização: do mesmo modo que as agremiações religiosas não pautam mais a totalidade das crenças e práticas religiosas dos entrevistados, a participação política em grupos organizados não funciona mais como uma agência socializadora na construção de opiniões, adesões ou identidades políticas dos estudantes de Ciências Sociais, não estrutura mais o horizonte ético e existencial dos posicionamentos dos alunos. Da mesma forma como é possível acreditar em Deus ou em espíritos sem participar de um grupo religioso, é possível ser tão politizado como qualquer militante sem necessariamente ter de submeter-se a disciplinas partidárias, ritos de rebelião ou expe- 
rimentar a chama sagrada do assembleísmo estudantil. A antiga individualização pela política, que marcava o estudante com uma espécie de religiosidade secular, parece ter sido colonizada por um individualismo mais flexivel, mais subjetivo e com menor nível de articulação de certezas políticas e religiosas.

Além de seus méritos intrínsecos, esta pesquisa ajuda a desmistificar uma representação unívoca do estudante de Ciências Sociais, enfrentando imagens niveladoras sobre a visão de mundo, origem social e projetos desses alunos.

$\mathrm{O}$ pertencimento às Ciências Sociais em si mesmo, o ato de definir-se por este curso, não deixa de configurar uma tomada de posição face à baixa estima social dessa profissão no espectro de possibilidades profissionais da universidade brasileira. As Ciências Sociais ainda sofrem de uma baixa credibilidade, como caminho pouco recomendado pelas famílias de camadas médias a seus filhos frente a cursos como engenharia, medicina, arquitetura e direito. Muitas vezes sendo o resultado de uma opção tardiamente amadurecida na trajetória de vida do estudante, sua representação social ainda está freqüentemente associada à política e às artes. Ou seja, mais uma vocação do que uma profissão ${ }^{2}$, seria todo um código ${ }^{3}$ e um estilo de vida (e, por que não dizer, uma recusa) que definiria essa opção, contrariamente à medicina ou ao direito, onde as redes hierarquizadas de poder, prestígio e acesso a postos profissionais funcionam tanto como instâncias de controle corporativo do desempenho normalizado da profissão quanto como provedoras da identidade sócio-profissional de seus membros. Em certo sentido, esse

\footnotetext{
${ }^{2}$ Bem entendido, a suposta oposição entre vocação e profissão deriva da representação social em questão, sendo, portanto, mais uma imagem difusa na sociedade do que um reflexo fiel das condições efetivas de exercício de profissões ligadas à obtenção do título em Ciências Sociais.

${ }^{3}$ Foi Regina Novaes, em artigo pioneiro de 1994, quem lançou essa idéia, além de ser a inspiradora dessa pesquisa.
} 
status ambíguo de uma identidade sempre transitória, oscilante entre a política, a sociabilidade acadêmica e os ecos de atitudes difusamente críticas e artisticamente vanguardistas, ajuda a compor um espaço de possibilidades para a constituição da auto-imagem dos estudantes de Ciências Sociais. O que, é claro, tem mais a ver com uma imagem popularizada da identidade do estudante do que com o cotidiano do profissional das Ciências Sociais e que, digase de passagem, sofre a concorrência de novos modelos, os quais propõem a vida profissional como uma carreira e as Ciências Sociais mais como um saber especializado do que como uma visão de mundo ou um estilo de vida.

Conclusão: a importância do contexto histórico regional.

Numa tentativa geral de explicação, uma primeira aproximação dos resultados da UFRGS apontaria, no caso da religião, para a expressão da redefinição pluralizante, heterodoxa, privatizante e mercadológica do campo religioso, na esteira de tendências mais gerais na sociedade brasileira ${ }^{4}$. A não ser em segmentos evangélicos, pouco representados na pesquisa, a identidade religiosa não opera como antes na demarcação de fronteiras para a sociabilidade e construção de grupos nos espaços urbanos da sociedade brasileira. Já presente nos antigos fenômenos do sincretismo, de duplo pertencimento e do trânsito religioso, a tendência à privatização da consciência religiosa atingiria o seu cume no ethos blasé e hedonista das camadas médias urbanas atuais. O fato é que os estudantes de Ciências Sociais matizam essas tendências sociológicas mais gerais na universidade, onde se reflete o peso relativo que ocupam as classes médias no espaço urbano de Porto Alegre. Para estes seg-

\footnotetext{
${ }^{4}$ Entre as inúmeras reflexões sobre a religiosidade na moderna sociedade brasileira, remeto a Oro (1997).
} 
mentos sociais, nos quais se inclui a clientela potencial das Ciências Sociais, as últimas décadas assistiram ao cruzamento do individualismo psicologizante e hedonista com a politização à esquerda, compondo o atual campo de possibilidades nas tomadas de posição religiosas, políticas e de estilos de vida dos acadêmicos pesquisados. Ora, esse ambiente favorece o que chamei de "núcleo de secularismo", onde atitudes dominantes de indiferença e incredulidade face à religião não significam apatia ética ou falta de busca de sentido imanente ou transcendente, mas indicam que vivemos uma situação de transição, mesmo no segmento mais exposto aos modernos processos de racionalização e de desencantamento do mundo.

De outra parte, não é de pouca importância para a compreensão da situação local a história singular das elites gaúchas, cuja relação com a religião católica sempre esteve permeada por um contexto mais reflexivo do que tradicional ${ }^{5}$, pelo menos desde o ingresso do Positivismo na República Velha, projeto que não por acaso esteve ligado à construção de um ensino público e, posteriormente, da universidade como fator estratégico na elevação intelectual e política da sociedade gaúcha.

Assim, se algo especifica a UFRGS em relação a outras universidades situadas no mesmo espaço urbano, é um certo agenciamento histórico de tendências ideológicas e (anti)religiosas que se em torno do secularismo do espaço público ali encenado. Não se pode esquecer que o Rio Grande do Sul, além do Positivismo, foi cenário de maçons, anarquistas, comunistas, espíritas e livres-pensadores, abrigando

\footnotetext{
${ }^{5}$ Estou aqui me valendo da distinção de Cândido Camargo (citada em Prandi \& Pierucci, 1996) entre uma religiosidade tradicional, fruto mais da herança do que do questionamento, e de outra, "internalizada", produto da dúvida, da escolha e da conversão, com custos tão altos quanto capaz de afinar-se com uma racionalização individual. O espiritismo tem um roteiro histórico inverso: surge reflexivo e dissidente e tende a tornar-se tradicional e respeitável.
} 
também uma forte tradição política, cívica e oposicionista, que sempre permeou a universidade. Deste modo, trata-se ir além de uma leitura fechada e vislumbrar nos resultados da pesquisa as incidências de um ideário da modernidade, consubstancial à idéia de universidade pública, não apenas como locus de atualização de uma determinada tradição democrático-cívica (que atrai, por afinidades diversas, as tendências secularistas e espíritas), mas também como categoria emblemática e sobredeterminada de identidades que ali encontraram um ambiente cultural favorável, entre as quais o secularismo e o espiritismo, além do consagrado espaço de contestação “à esquerda”, que parecia caracterizá-la anteriormente.

\section{Referências Bibliográficas}

LEWGOY, Bernardo. Os espíritas e as letras: um estudo antropológico sobre cultura escrita e oralidade no espiritismo kardecista. Tese de Doutorado, São Paulo, USP, FFLCH, 2000.

NOVAES, Regina. "Religião e política: sincretismos entre alunos de ciências sociais”. Comunicações do ISER, Rio de Janeiro, 1994.

ORO, Ari. "Modernas formas de crer". Revista Eclesiástica Brasileira, n. 225, março 1997, pp. 39-56.

PIERUCCI, Antônio Flávio \& PRANDI, Reginaldo. A realidade social das religiões no Brasil. São Paulo: Hucitec, 1996.

STEIL, Carlos Alberto, HERRERA, Sonia Reyes e ALVES, Daniel. "Religião e Política entre os alunos de Ciências Sociais: a definição de um perfil". Debates do NER, n. 2, Porto Alegre, UFRGS, 2001. 